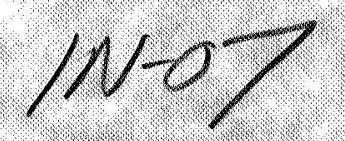

NASA Technical Memorandum 106054

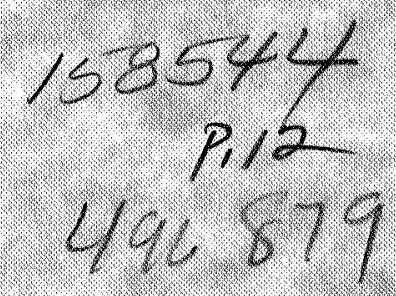

\title{
Experimental Performance of a Ventral Nozzle With Pitch and Yaw Vectoring Capability for SSTOVL Aircraft
}

Barbara S. Esker and Jack G. McArdle Lewis Research Center Cleveland, Ohio

Prepared for the Aerospace Atlantic Conference sponsored by the Society of Automotive Engineers

Dayton, Ohio, April 20-23, 1993 


\title{
EXPERIMENTAL PERFORMANCE OF A VENTRAL NOZZLE WITH PITCH AND YAW VECTORING CAPABILITY FOR SSTOVL AIRCRAFT
}

\author{
Barbara S. Esker and Jack G. McArdle \\ National Aeronautics and Space Administration \\ Lewis Research Center \\ Cleveland, Ohio 44135
}

\begin{abstract}
Aircraft with supersonic, short takeoff and vertical landing capability have been proposed to replace some of the current high-performance aircraft. Several of these configurations use a ventral nozzle in the lower fuselage, aft of the center of gravity, for lift or pitch control. Internal vanes canted at $20^{\circ}$ were added to a swivel-type ventral nozzle and tested at tailpipe-to-ambient pressure ratios up to 5.0 on the Powered Lift Facility at NASA Lewis Research Center. The addition of sets of four or seven vanes decreased the discharge coefficient of the nozzle by at least 6 percent and did not affect the thrust coefficient. Side force produced by the nozzle with vanes was 14 percent or more of the vertical force. In addition, this side force caused only a small loss in vertical force in comparison to the nozzle without vanes. The net thrust force was $8^{\circ}$ from the vertical for four vanes and $10.5^{\circ}$ for seven.
\end{abstract}

\section{INTRODUCTION}

Aircraft with supersonic, short takeoff and vertical landing (SSTOVL) capability have been proposed as possible replacements for some of the current high-performance aircraft. Several of the configurations utilize engine exhaust gases ducted from the tailpipe to the main lift devices (fig. 1). The main lift devices-which could include ejectors, burners, or lift fans-may be accompanied by a ventral nozzle located in the underside of the fuselage, aft of the center of gravity. The ventral nozzle, depending on its size, may be used primarily for lift or pitch control. NASA Lewis Research Center has been involved in several programs to ready the technologies for the development of such an aircraft. These programs have included studies of ventral nozzles, tailpipe and offtakes, hot gas ingestion, and integrated propulsion-airframe controls.

The original ventral nozzle program, which was initiated in 1988, compared the experimental performance and analytically predicted performance of a generic, rectangular ventral nozzle system. The results of this work are described in references 1 to 4. As part of this program the swivel nozzle, a particular type of ventral nozzle, was tested in 1990 . By pivoting the outer shell up to $23^{\circ}$ on either side of the $90^{\circ}$ pure lift position, this nozzle (fig. 2) could vector the ventral flow forward and aft for lift or pitch control. Detailed results from testing this nozzle are given in reference 5.

The swivel nozzle was then modified to include fixed internal vanes (fig. 3), canted at a $20^{\circ}$ angle, to create side force for yaw vectoring. These vanes were designed for the nozzle outer shell at a fixed, $90^{\circ}$ position. The nozzle was tested with two different sets of internal vanes: four vanes (as shown in fig. 3) and seven vanes. The objective of the test program was to establish the capability of the swivel nozzle with internal vanes to produce side force. This paper presents the performance characteristics of the nozzle with the internal vanes and compares them to the characteristics of the nozzle without vanes.

Both the original swivel nozzle and the swivel nozzle with the internal vanes were tested at NASA Lewis on the Powered Lift Facility (PLF). Steady-state thrust and flow performance up to a tailpipe pressure ratio of 5 were measured. 


\section{APPARATUS AND INSTRUMENTATION}

The swivel nozzle (fig. 2(a)), which was based on a round nozzle model reported in reference 6, was approximately one-third scale with exit area dimensions of 11.68 by $34.29 \mathrm{~cm}$. It could vector the ventral flow forward and aft by rotating the outer shell about an axis perpendicular to both the tailpipe and ventral axes. Shell rotation was up to $23^{\circ}$ on either side of the midposition. The swivel nozzle is shown in its fully rotated position in figure 2(b).

This nozzle was then modified to include a set of fixed internal vanes, canted at a $20^{\circ}$ angle, to produce side force. Photographs of the internal vanes and the nozzle modified to include the internal vanes are given in figures 3(a) and (b), respectively. A schematic of the nozzle configuration is shown in figure 4 . The internal vanes simulated a vaneset that could be deflected on pivot axes in the nozzle exit plane. This arrangement, in comparison with vanes hinged upstream in the nozzle, would minimize exit flow area changes as the vanes were deflected. Additional details of the swivel nozzle with the internal vanes are given in the appendix.

Figure 4 also illustrates the geometrically set angles associated with the nozzle, which are defined as follows:

(1) The swivel vector angle is the angle formed between the tailpipe axis and the normal to the exit plane of the nozzle.

(2) The internal vane angle is the angle formed between the vertical and the angle of the vanes.

Both the original swivel nozzle and the swivel nozzle with internal vanes were tested on a model tailpipe configuration (fig. 5). Immediately upstream of the tailpipe was a reducer section from the 60.96-cm diameter facility piping to the 34.29-cm diameter tailpipe. The reducer section contained flow conditioners and a boundary layer trip. The model tailpipe was approximately one-third scale in diameter of modern military engine tailpipes and contained a rectangular ventral duct mounted perpendicular to the tailpipe centerline. Both the tailpipe and ventral duct were modular in construction to allow for testing a wide variety of ventral nozzles. The ventral duct $(33.02$ by $24.13 \mathrm{~cm})$ contained an adapter block to reduce the flow area to that of the swivel nozzle inlet area $(33.02$ by $17.78 \mathrm{~cm})$ and to round off the entrance into the ventral duct (enabling the flow to turn smoother into the ventral duct). Lastly, the aft end of the tailpipe was closed with a blind flange to simulate a closed cruise nozzle as may be used for a SSTOVL aircraft in hover.

Testing was done on the Powered Lift Facility (PLF) at NASA Lewis. The PLF (fig. 6) is a large thrust stand that can measure thrust force levels in the vertical, axial, and lateral directions as well as moments about all three axes. Surrounding the PLF is an acoustically treated, geodesic dome (not shown in fig. 6) with a 19.81-m radius. This dome was designed to effectively contain the noise generated by the nozzle testing. Additional details of the PLF are given in the appendix of reference 7.

The experimental model was supplied with high-pressure air at ambient temperatures from Lewis' high-pressure air system. Model inlet pressures were up to $493.78 \mathrm{kPa}$ absolute, and flow rates were up to $39.92 \mathrm{~kg} / \mathrm{sec}$. Facility flow rates were measured upstream of the experimental model with an American Society of Mechanical Engineers (ASME) flow-measuring nozzle in the facility air-supply line. The measurement uncertainty was \pm 0.5 percent, including both scatter and systematic errors.

Instrumentation consisted of steady-state temperatures and pressures. Air total temperatures were measured by thermocouples in the duct immediately upstream of the tailpipe. The tailpipe reference location (station 5, fig. 5) contained 20 total-pressure tubes located on centers of equal area. Static pressure measurements were made in the tailpipe and ventral duct. The data acquisition systems included up to 200 available analog channels, and steady-state pressures 
measured by an electronically scanned pressure measurement system with 372 available data channels. Data were batch processed on a NASA Lewis mainframe computer system.

\section{TESTING PROCEDURE}

Performance testing of the original swivel nozzle had consisted of measuring steady-state thrust and flow performance for the nozzle at swivel vector angles from $70^{\circ}$ to $110^{\circ}$ over a range of tailpipe-to-ambient pressure ratios from 1 to 4.5 (ref. 5). The testing had indicated that the internal total pressure loss as the flow turned from the tailpipe into the ventral duct was less than 1.5 percent. For the recent performance testing of the swivel nozzle with internal vanes, steady-state thrust and flow performance data were obtained at the $90^{\circ}$ swivel vector angle. This testing was conducted on the nozzle assembled with no vanes, the nozzle with a set of four internal vanes (shown in figs, 3 and 4), and the nozzle with a set of seven internal vanes.

\section{RESULTS AND DISCUSSION}

The results presented include flow and thrust performance parameters (in terms of the discharge and thrust coefficients) for both the original swivel nozzle configuration and the nozzle with both four and seven internal vanes. These results, together, indicate the performance of the nozzle during pitch and yaw vectoring.

Figure 7 shows the variation of discharge coefficient $C_{D}$ with swivel vector angle for the original swivel nozzle configuration (ref. 5). The discharge coefficient was defined as the ratio of actual flow through the ventral nozzle to the isentropic, ideal flow calculated with the measured pressure at the tailpipe reference station (station 5). The discharge coefficient increased with tailpipe-to-ambient pressure ratio and also increased slightly as the swivel vector angle increased (i.e., flow being vectored more and more back towards the tailpipe inlet as shown in fig. 4). Flow visualization in a generic ventral system (refs. 1 to 4 ) had indicated that the flow from the tailpipe into the ventral duct overturned (i.e., turned greater than $90^{\circ}$ ). Similar internal flow behavior was found to exist with the swivel nozzle. As a result, the swivel vector angle of $110^{\circ}$ complemented this tendency of the flow to overturn, resulting in the increased discharge coefficient.

Figure 8 gives the variation in discharge coefficient for the swivel nozzle with and without internal vanes for the $90^{\circ}$ swivel vector angle. The discharge coefficient was reduced by the presence of the internal vanes. At high tailpipe-to-ambient pressure ratios, this reduction can be partially accounted for by the reduced flow area, which was approximately proportional to the cosine of the $20^{\circ}$ internal vane angle (i.e., directly related to the shift of the geometric throat due to the angle of the vanes). The drag on the vanes also would have contributed to the reduced discharge coefficient. The nozzle with four vanes showed approximately a 6-percent decrease $\left(C_{D}=0.867\right.$ at a tailpipe-to-ambient pressure ratio of 4.0$)$ in system flow performance from the nozzle without vanes. Similarly, the nozzle with seven vanes showed an approximately 8-percent decrease $\left(C_{D}=0.839\right.$ at a tailpipe-to-ambient pressure ratio of 4.0$)$.

Figure 9 shows the variation of thrust coefficient for the swivel nozzle with internal vanes. The thrust coefficient was defined as the resultant actual thrust divided by the ideal thrust calculated with the actual flow and the reference tailpipe total pressure. For the nozzle with vanes, the thrust coefficient is shown as a fraction of the thrust coefficient for the swivel nozzle without vanes. Both the nozzle with four and with seven vanes resulted in approximately the same thrust coefficients (at a tailpipe-to-ambient pressure ratio of 4.0) as the nozzle without vanes. These results indicated that the vanes do not affect the thrust coefficient except at low 
tailpipe-to-ambient pressure ratios. Also, previous testing had indicated that the thrust coefficient for the swivel nozzle was not affected by the swivel vector angle.

Figure 10 shows the ratio of the vertical thrust produced by the swivel nozzle with vanes to the vertical thrust produced by the same nozzle without vanes. These thrust values were normalized to the same flow by using the respective discharge coefficients. The nozzle with four vanes produced 99-percent vertical thrust at a tailpipe-to-ambient pressure ratio of 4.0 and, similarly, the nozzle with seven vanes produced 98-percent vertical thrust in comparison to the swivel nozzle without vanes.

The capability of the swivel nozzle with internal vanes to produce side force is shown in figure 11. The nozzle with four vanes produced less side force component than the nozzle with seven vanes. At a tailpipe-to-ambient pressure ratio of 4.0, the side force produced with four vanes was approximately 13.8 percent of the vertical force. In comparison, the nozzle with seven vanes produced a side force equal to $\mathbf{1 7 . 8}$ percent of the vertical force at the same pressure ratio. For both sets of vanes, the percentage of side force relative to vertical force decreased with increasing tailpipe-to-ambient pressure ratio.

Figure 12 shows the effective flow angle produced by the swivel nozzle with four and seven internal vanes. This effective flow angle was directly calculated from the magnitudes of the vertical and side force component produced by the nozzle. The results indicate that the effective flow angle was not equal to the geometric vane angle of $20^{\circ}$. At a tailpipe-to-ambient pressure ratio of 4.0, the effective flow angles produced by the nozzle with four and seven internal vanes were $8^{\circ}$ and $10.5^{\circ}$, respectively.

\section{CONCLUDING REMARKS}

A swivel nozzle that had been previously tested to establish its capability to vector the ventral flow forward and aft was tested with two sets of fixed internal vanes, canted at a $20^{\circ}$ angle, to create side force. The objective of the experimental study was met; that is, performance characteristics of the nozzle with internal vanes were obtained for comparison to the nozzle without vanes.

The testing of the swivel nozzle with internal vanes showed, at a tailpipe-to-ambient pressure ratio of 4.0, that the discharge coefficient decreased by at least 6 percent and that the thrust coefficient was unaffected by the internal vanes. Also, an offset was found to exist between the set internal vane angle of $20^{\circ}$ and the effective flow angle. The effective flow angle was calculated directly from the side and vertical force components. This angle, at a tailpipe-toambient pressure ratio of 4.0, was found to be $8^{\circ}$ for the swivel nozzle with four vanes and $10.5^{\circ}$ for the nozzle with seven vanes. Previous testing (ref. 5) showed the original swivel nozzle to have good flow and thrust performance for a range of swivel vector angles from $70^{\circ}$ to $110^{\circ}$ ( $\pm 20^{\circ}$ from the midposition). Within this vectoring range, the discharge coefficient of the swivel nozzle increased slightly as the swivel vector angle increased. This testing also showed that the thrust coefficient was unaffected by swivel vector angle.

In general, testing indicated that directing the ventral jet at subsonic velocities resulted in efficient vectoring of the ventral flow. This innovative vectoring scheme could be applied to a SSTOVL aircraft to increase maneuverability and control. 


\section{APPENDIX - VANE DESIGN PROCEDURE}

The nozzle and vanes used in this study are illustrated in figures 3 and 4 . The equally spaced internal vanes had a thin, aerodynamic shape and were fixed at $20^{\circ}$. They were positioned as if deflected on pivot axes in the nozzle exit plane. This arrangement, in comparison to vanes hinged upstream in the nozzle, tends to minimize exit flow area changes as the vanes are deflected to various angles. If the nozzle shell were moved at the same time to change the swivel vector angle, each vane would have to consist of plates that slide past each other to conform to the changing shape of the flow channel. (In this regard, vanes in the form of paddles in the flow would not have to be made of sliding plates if they did not reach the shell walls. The paddles probably would behave as vanes but would be inefficient because of spillage between the paddles and the shell wall.)

The number of vanes was chosen as follows (see fig. 13). The original swivel nozzle had been found to turn its exhaust jet almost $20^{\circ}$ with the outer shell pivoted $20^{\circ}$ (ref. 5). The unmatched shell wall area that accomplished that jet turn, projected to the vertical plane (as indicated in fig. 13), was measured from drawings. From momentum principles, it was assumed that the same area would deflect the jet in another direction if the pressure on the wall were equivalent. Thus, the vertical projected area of the unmatched shell wall area was divided by the projected area available in each vane, resulting in 3.4 vanes (built as four complete vanes). The other set of vanes was arbitrarily chosen as seven vanes. This method resulted in a design which, experimentally, did not produce the intended jet-turning angles. No flow analyses were done to

determine the reason for this result. However, it is likely that the pressure on the "suction" side of each vane was high enough to substantially oppose the pressure level on the "pressure" side. In contrast, for the nozzle without vanes, there was no wall (ambient pressure) opposite the swiveled shell.

\section{REFERENCES}

1. McArdle, J.G.; and Smith, C.F.: Experimental and Analytical Study of Close-Coupled Ventral Nozzle for ASTOVL Aircraft. NASA TM-103170, 1990.

2. McArdle, J.G.; and Smith, C.F.: Flow Studies in Close-Coupled Ventral Nozzles for STOVL Aircraft. SAE Paper 901033, 1990.

3. Smith, C.F.; and McArdle, J.G.: Analysis of Internal Flow in a Ventral Nozzle for STOVL Aircraft. AIAA Paper 90-1899, 1990.

4. Smith, C.F.; and McArdle, J.G.: Analysis of Internal Flow in a Ventral Nozzle. J. Propuls. Power, vol. 8, no. 2, Mar.-Apr. 1992, pp. 530-536.

5. Esker, B.S.; and McArdle, J.G.: Performance Characteristics of a One-Third-Scale, Vectorable Ventral Nozzle for SSTOVL Aircraft. AIAA Paper 90-2271, 1990.

6. McArdle, J.G.: Internal Characteristics and Performance of Several Jet Deflectors at Primary-Nozzle Pressure Ratios Up To 3.0. NACA TN-4264, 1958.

7. Esker, B.S.; and Perusek, G.P.: Experimental Performance of Three Design Factors of Ventral Nozzles for SSTOVL Aircraft. AIAA Paper 92-3789, 1992. 


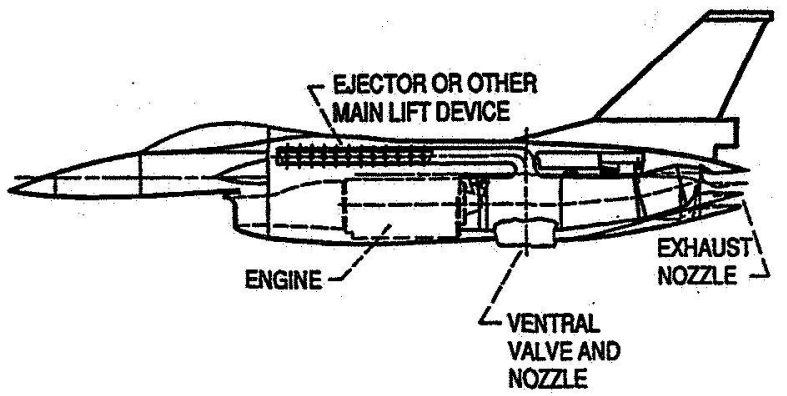

Figure 1. Schematic of proposed STOVL propulsion system utilizing engine exhaust gases for main lift devices and ventral nozzle.

\section{ORIGINAL PAGE \\ BLACK AND WHITE PHOTOGRAFM}

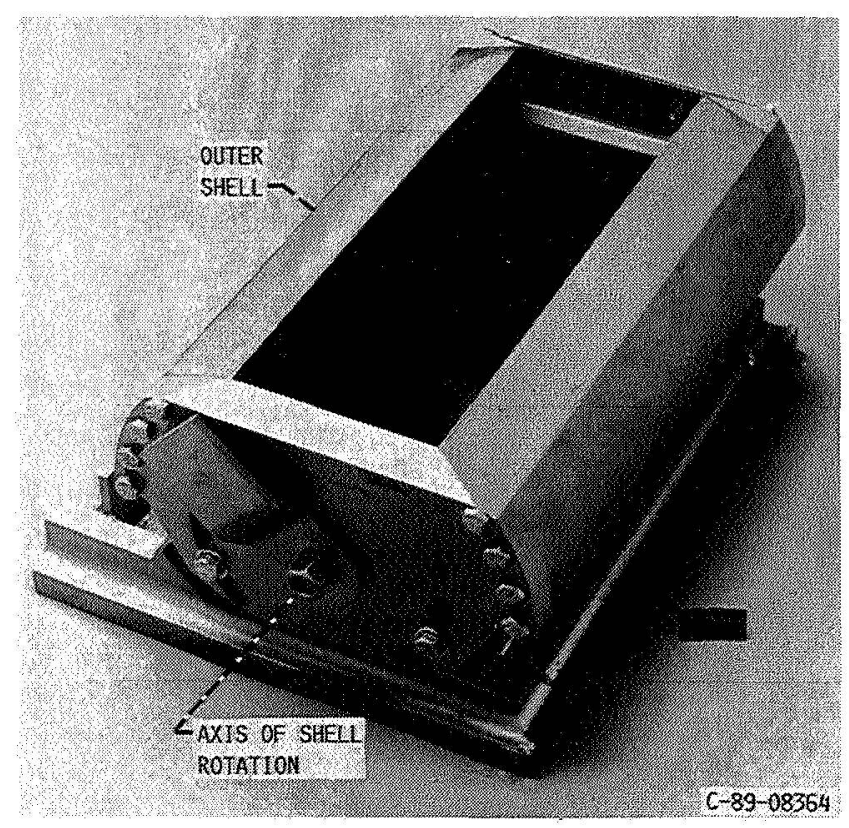

(a) In midposition.

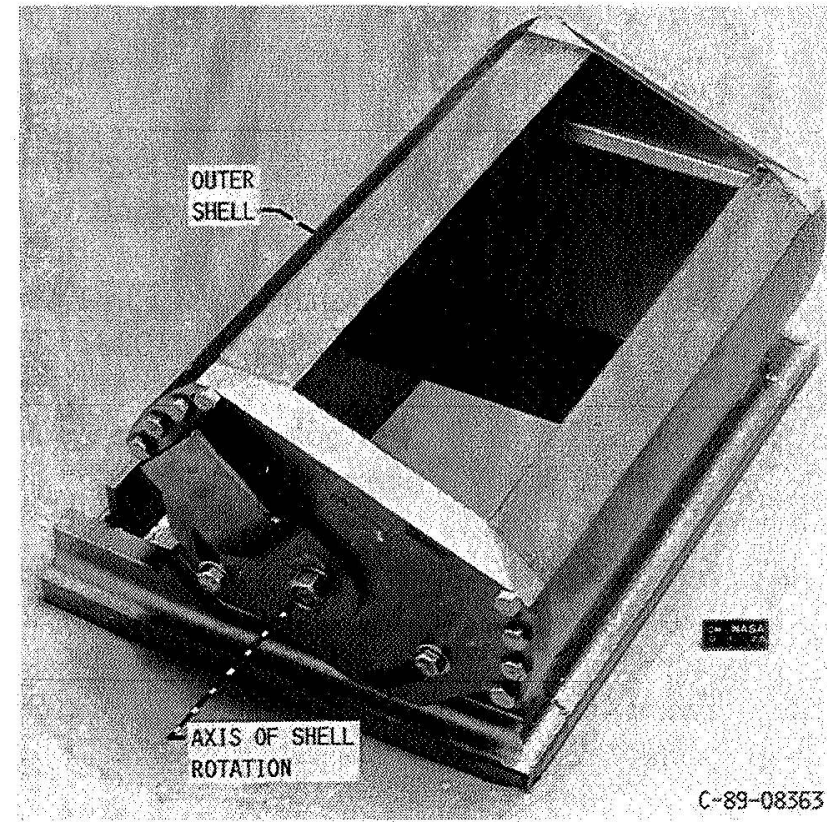

(b) In rotated position.

Figure 2.-Original swivel nozzle configuration. 


\section{ORIGINAL PAGE \\ BLACK AND WHITE PHOTOGRAHH}

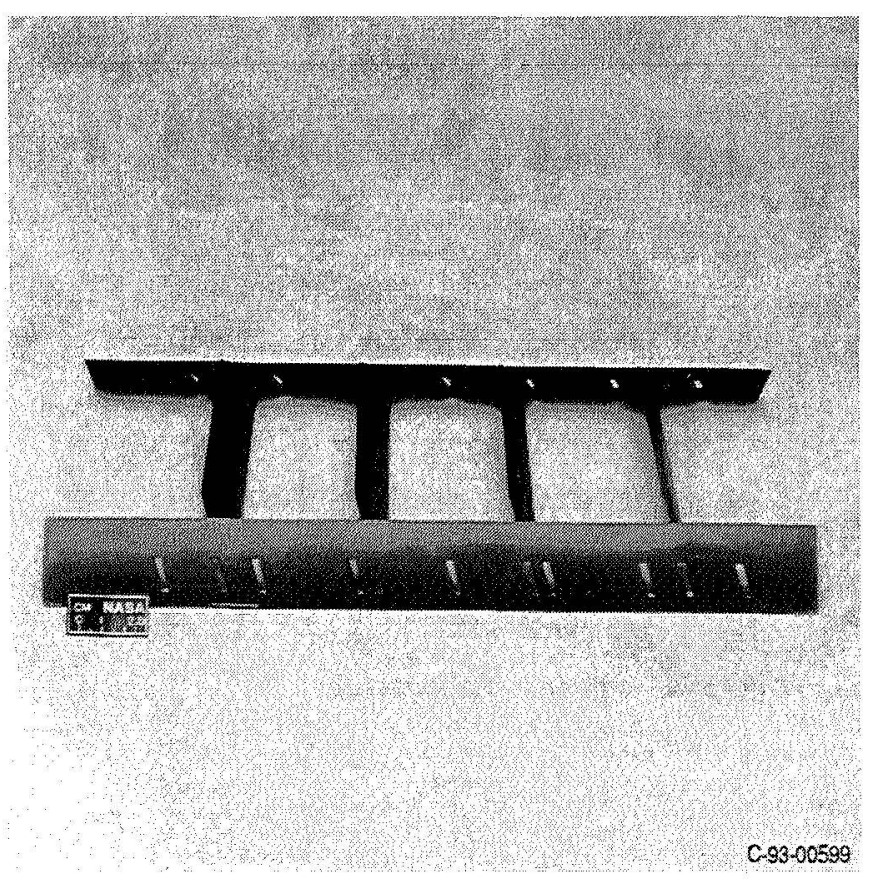

(a) Set of four vanes.

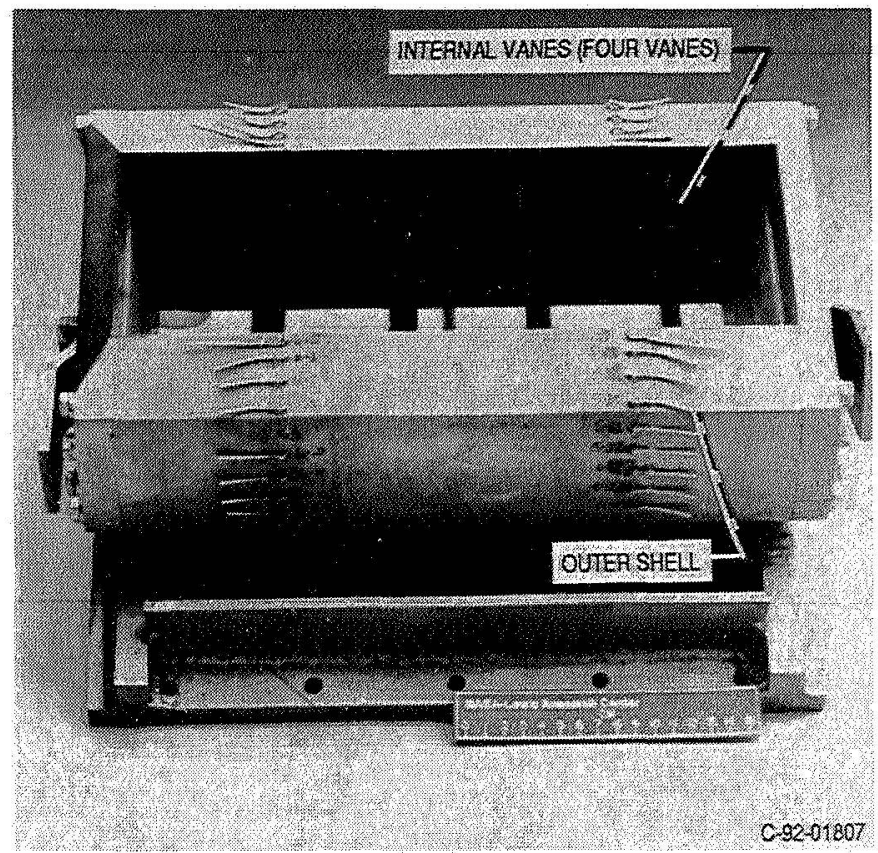

(b) Set of four vanes assembled into the swivel nozzle. Nozzle shown photographed at an oblique angle.

Figure 3.-internal vanes for side force.

SWIVEL VECTOR ANGLE

INTERNAL VANE ANGLE
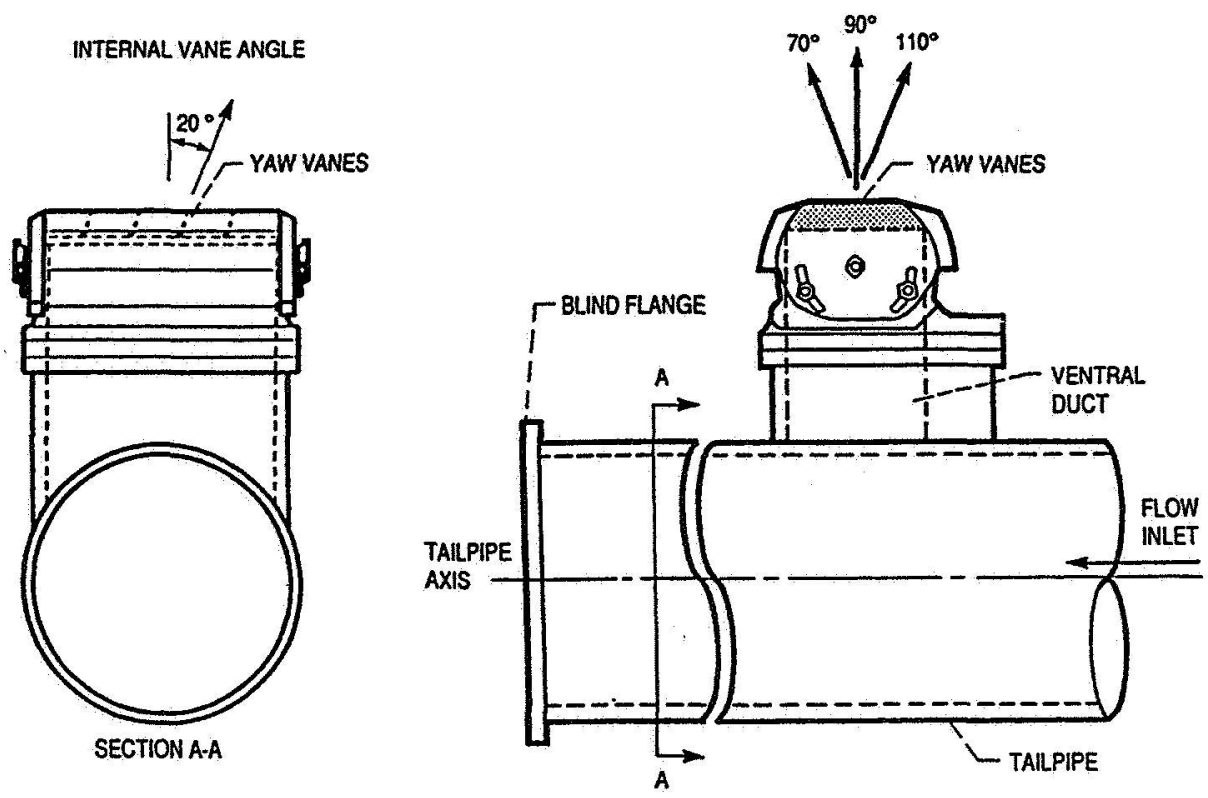

Figure 4.-Geometric vector angles defined for swivel nozzle configuration. 


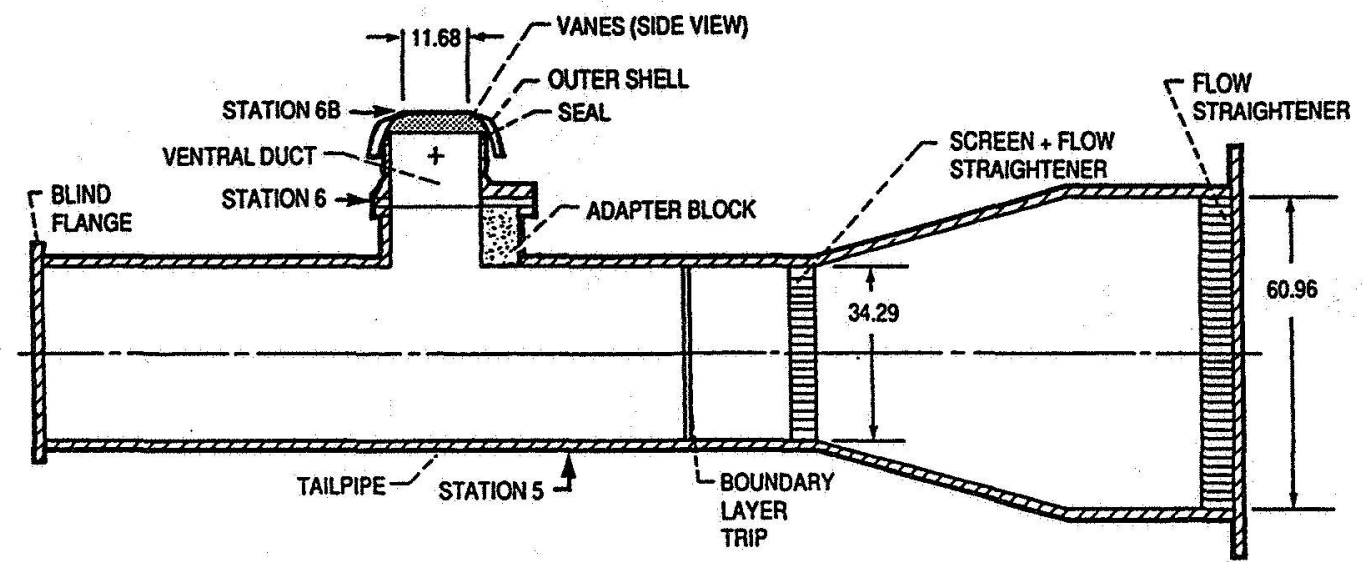

Figure 5.-Swivel nozzle mounted on model tailpipe. (All dimensions given in centimeters.)

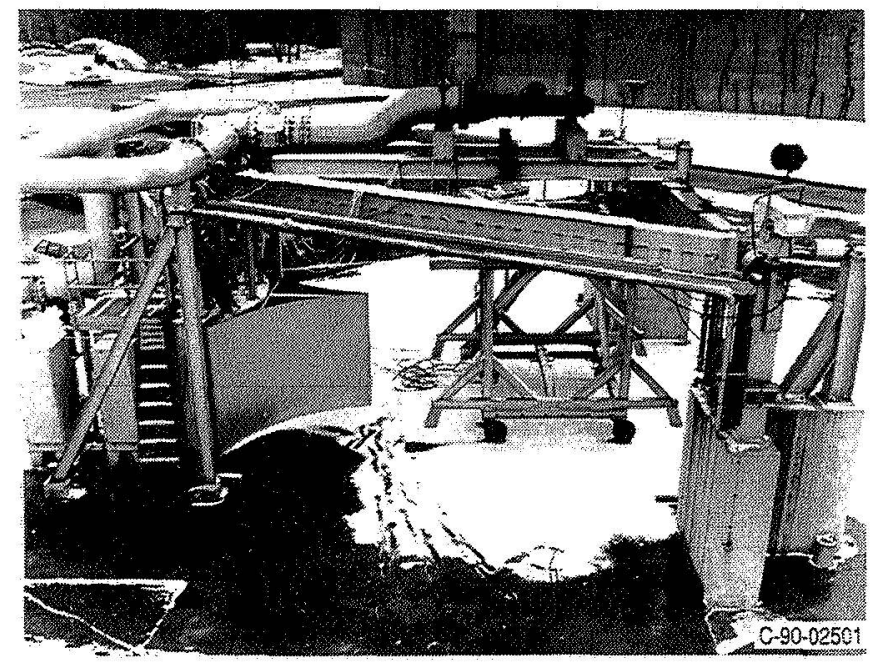

Figure 6.-Powered Lift Facility at NASA Lewis Research Center.

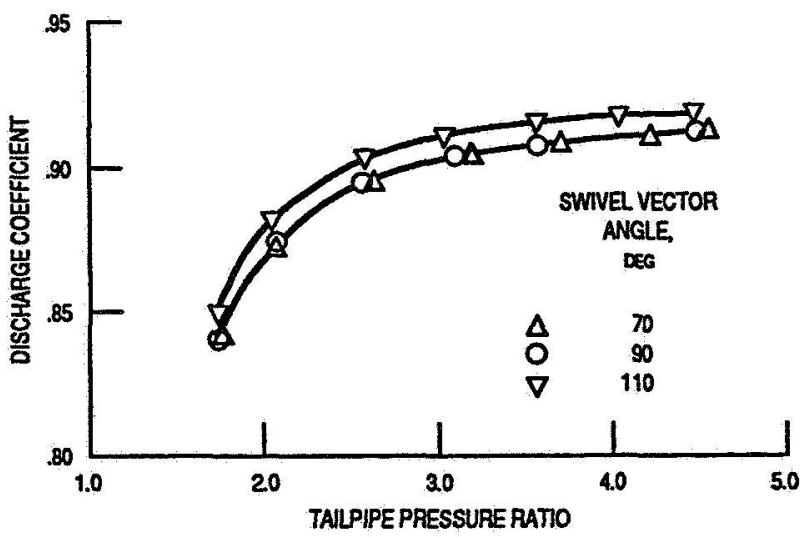

Figure 7.-Variation of discharge coefficient for three swivel vector angles for original swivel nozzle without vanes. (Data from ref. 5.) 


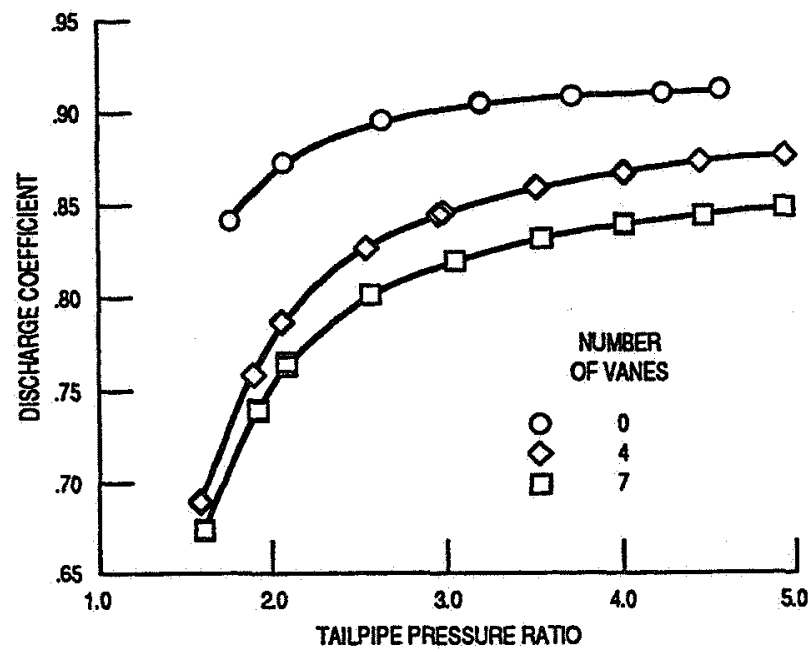

Figure 8.-Variation of discharge coefficient for swivel nozzle with four and with seven internal vanes.

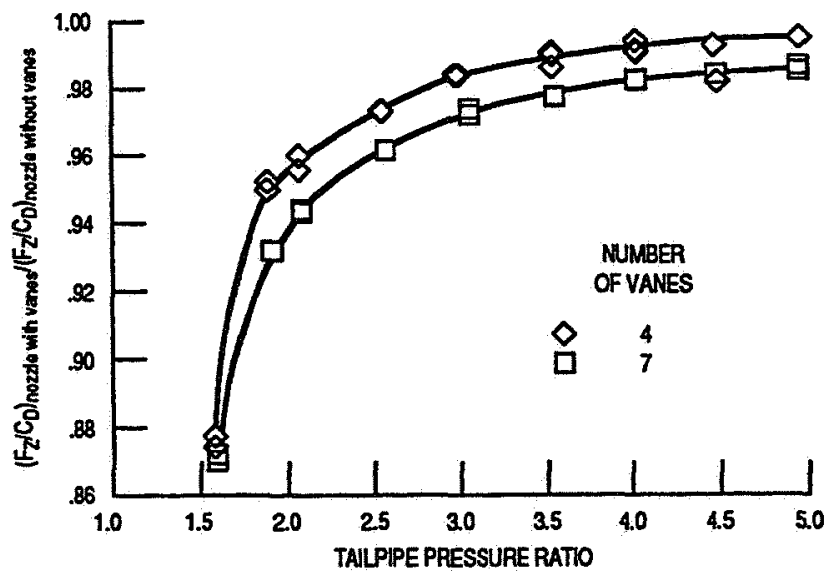

Figure 10.-Vertical force, $F_{Z}$, produced by swivel nozzle with four and with seven internal vanes as a fraction of vertical force produced by swivel nozzle without vanes. Vertical forces were normalized by their respective discharge coefficients, $C_{D}$.

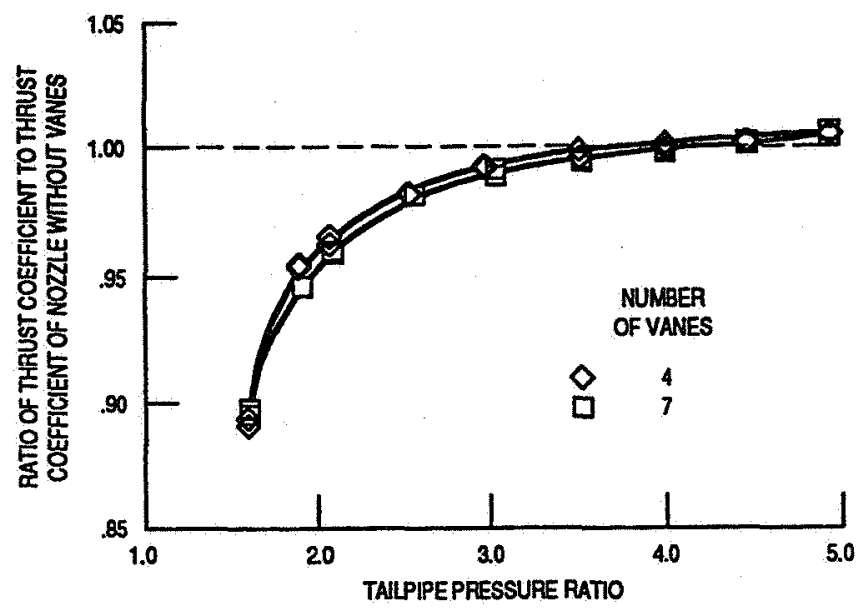

Figure 9.-Variation of thrust coefficient for swivel nozzle with four and with seven internal vanes. Shown as a fraction of thrust coefficient for swivel nozzle without vanes.

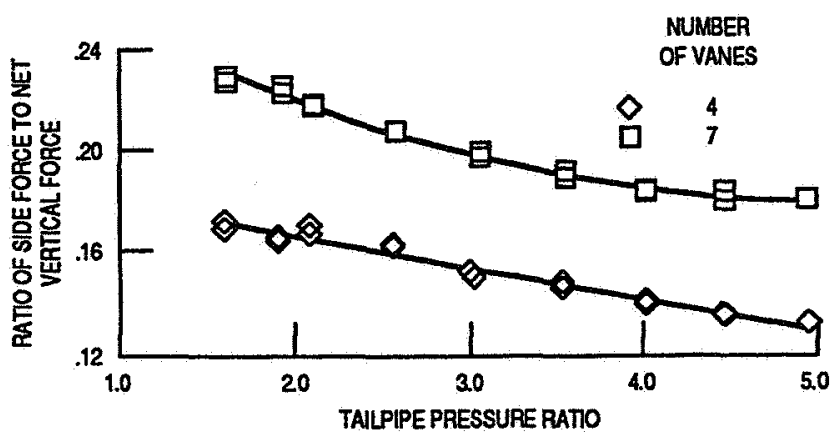

Figure 11. - Side force as a fraction of vertical force produced by swivel nozzle with four and with seven intemal vanes. 


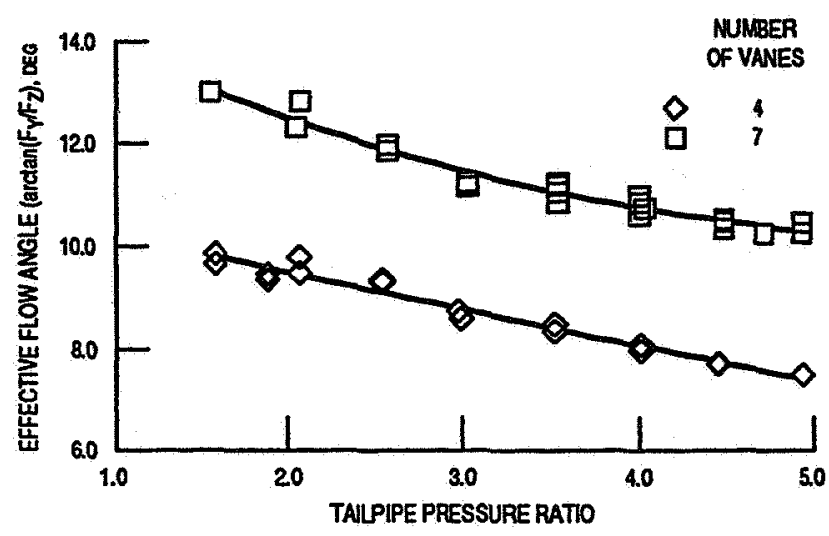

Figure 12. - Effective flow angle for swivel nozzle with four and with seven vanes. Arctan (side force component, FY/vertical force component, $F_{Z}$.

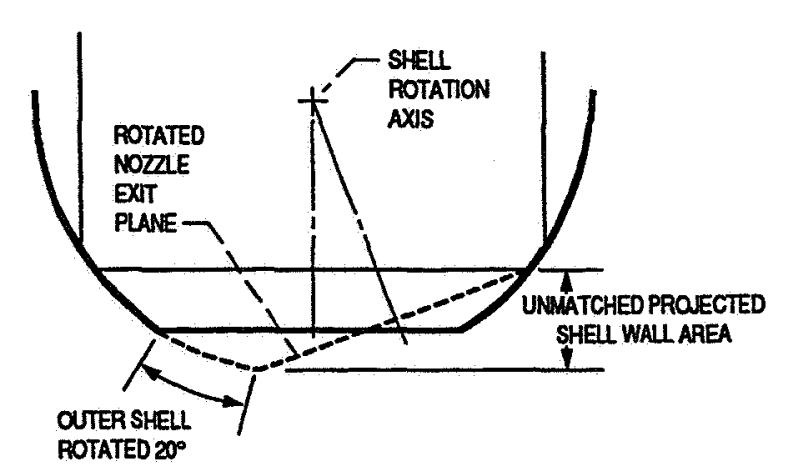

(a) Unmatched wall area for rotated swivel nozzle without internal vanes.

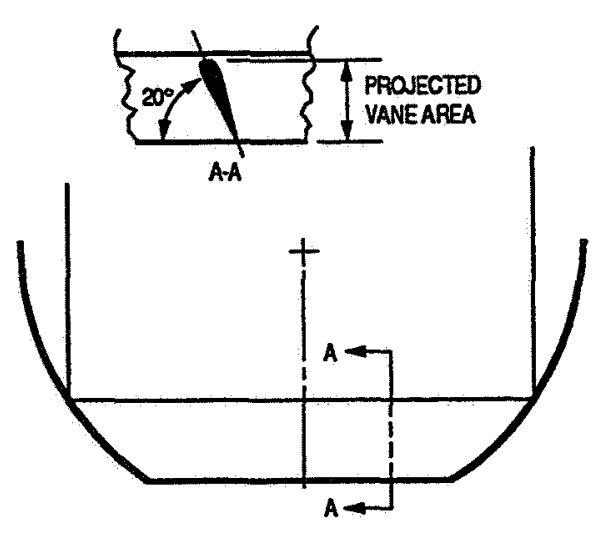

(b) Swivel nozzle with internal vanes.

Figure 13.-Internal vanes for yaw vectoring in swivel nozzle. 
Public reporting burden for this collection of information is estimated to average 1 hour per response, including the time for reviewing instructions, searching existing data sources, gathering and maintaining the data needed, and completing and reviewing the collection of information. Send comments regarding this burden estimate or any other aspect of this collection of information, including suggestions for reducing this burden, to Washington Headquarters Services, Directorate for Information Operations and Reports, 1215 Jefferson Davis Highway, Suite 1204, Arfington, VA 22202-4302, and to the Office of Management and Budget, Paperwork Reduction Project (0704-0188), Washington, DC 20503.

\begin{tabular}{r|r|r|} 
1. AGENCY USE ONLY (Leave blank) & $\begin{array}{r}\text { 2. REPOAT DATE } \\
\text { April } 1993\end{array}$ & $\begin{array}{r}\text { 3. REPORT TYPE AND DATES COVERED } \\
\text { Technical Memorandum }\end{array}$ \\
\hline
\end{tabular}

\section{TITLE AND SUBTITLE}

Experimental Performance of a Ventral Nozzle With Pitch and Yaw Vectoring Capability for SSTOVL Aircraft

\section{AUTHOR(S)}

Barbara S. Esker and Jack G. McArdle
5. FUNDING NUMBERS

WU-505-68-32

\section{PERFORMING ORGANIZATION NAME(S) AND ADDRESS(ES)}

National Aeronautics and Space Administration

Lewis Research Center

Cleveland, Ohio 44135-3191
8. Performing organization REPORT NUMBER

$\mathrm{E}-7648$

9. SPONSORING/MONITORING AGENCY NAMES(S) AND ADDRESS(ES)

10. SPONSORING/MONITORING AGENCY REPORT NUMBER

National Aeronautics and Space Administration

Washington, D.C. 20546-0001

NASA TM-106054

\section{SUPPLEMENTARY NOTES}

Prepared for the Aerospace Atlantic Conference sponsored by the Society of Automotive Engineers, Dayton, Ohio, April 2-23, 1993. Responsible person, Barbara S. Esker, (216) 433-8707.

12a. DISTRIBUTION/AVAILABILITY STATEMENT

12b. DISTRIBUTION CODE

Unclassified -Unlimited

Subject Category 07

\section{ABSTRACT (Maximum 200 words)}

Aircraft with supersonic, short takeoff and vertical landing capability have been proposed to replace some of the current high-performance aircraft. Several of these configurations use a ventral nozzle in the lower fuselage, aft of the center of gravity, for lift or pitch control. Internal vanes canted at $20^{\circ}$ were added to a swivel-type ventral nozzle and tested at tailpipe-to-ambient pressure ratios up to 5.0 on the Powered Lift Facility at NASA Lewis Research Center. The addition of sets of four and seven vanes decreased the discharge coefficient by at least 6 percent and did not affect the thrust coefficient. Side force produced by the nozzle with vanes was 14 percent or more of the vertical force. In addition, this side force caused only a small loss in vertical force in comparison to the nozzle without vanes. The net thrust force was $8^{\circ}$ from the vertical for four vanes and $10.5^{\circ}$ for seven.

\section{SUBJECT TERMS}

Exhaust nozzles; Thrust vector; Short takeoff aircraft; Vertical takeoff aircraft; Powered-lift aircraft

17. SECURITY CLASSIFICATION OF REPORT Unclassified
18. SECURITY CLASSIFICATION OF THIS PAGE Unclassified
19. SECURTYY CLASSIFICATION OF ABSTRACT Unclassified 